\title{
Bangladesh: COVID-19 Knowledge, Attitudes, Practices \& Needs-Responses from three rounds of data collection among adolescent girls in districts with high rates of child marriage
}

\author{
Sajeda Amin \\ Population Council \\ Ubaidur Rob \\ Population Council \\ Sigma Ainul \\ Population Council \\ Md. Irfan Hossain \\ Population Council \\ Forhana Rahman Noor \\ Population Council
}

See next page for additional authors

Follow this and additional works at: https://knowledgecommons.popcouncil.org/departments_sbsr-pgy

Part of the International Public Health Commons, and the Social and Behavioral Sciences Commons How does access to this work benefit you? Let us know!

\section{Recommended Citation}

Amin, Sajeda, Ubaidur Rob, Sigma Ainul, Md. Irfan Hossain, Forhana Rahman Noor, Iqbal Ehsan, and Mehnaz Manzur. 2020. "Bangladesh: COVID-19 Knowledge, Attitudes, Practices \& Needs-Responses from three rounds of data collection among adolescent girls in districts with high rates of child marriage," COVID-19 Research \& Evaluations brief. Dhaka: Population Council. 


\section{Authors}

Sajeda Amin, Ubaidur Rob, Sigma Ainul, Md. Irfan Hossain, Forhana Rahman Noor, Iqbal Ehsan, and Mehnaz Manzur 


\title{
Bangladesh: Covid-19 Knowledge, Attitudes, Practices \& Needs
}

\author{
Responses from three rounds of data collection among adolescent girls in districts with \\ high rates of child marriage
}

\section{Highlights}

- Overall awareness about the pandemic and knowledge about symptoms, contagion, and prevention are high. Awareness of asymptomatic spread remains low. While disease awareness has increased, adherence to social distancing remains a concern.

- Household income has rebounded slightly after lockdown was relaxed. However economic vulnerability is still evident. Respondents report eating less protein, buying fewer household goods and food, and not seeking health services.

- Prolonged school closures continue to take a toll. Most girls $(63 \%)$ think they will not be able to keep up with the next grade's lessons and 1 in 10 girls say they may not go back to school after reopening for reasons including gaps in learning, household economic problems, and marriage.

- Mental health indicators have worsened. Four out of five girls reported depressive symptoms, which have increased over time (61\%, 74\%, and 79\% in Rounds one, two, and three respectively).

- There is an increase over time in the proportion of girls who reported child marriage in their communities during COVID-19.

\section{Background}

From April 20-30, 2020, during a nationwide lockdown, the Population Council Bangladesh conducted the first round of a rapid phone-based survey on COVID-19 knowledge, attitudes, and practices (KAP). The survey randomly selected girls who had provided phone numbers during enrollment in a skills-building program that began before the pandemic. The survey's objective was to assess the impact of COVID-19 on adolescent lives and to design programs that would contribute to protecting girls and meet social distancing guidelines imposed by the government. Phone interviews were conducted with 479 girls living in the districts of Chapainawabganj, Kushtia, and Sherpur who were participants in a program focused on reducing child marriage by increasing school attendance and grade progression among girls ages 12 to $15 .{ }^{1}$ A follow-up survey was conducted from June 12-22, 2020, prior to the introduction of virtual skills sessions as school closure and social distancing protocols were in effect. The nationwide lockdown had been withdrawn by that time. A third round of remote data collection took place from September 5-11, 2020.

This brief presents the findings and comparisons from the three rounds of phone surveys:

- Round one: 479 girls

- Round two: 453 girls (95\%)

- Round three: 448 girls (94\%)

- Average age: 14 years

- In-school girls: $80 \%$. Completed some secondary education: $91 \%$

- Married girls (round one): $7 \%$

- Participating in income-generating activities (round one): $4 \%$

1 Amin, Sajeda, Ubaidur Rob, Masuma Billah, Sigma Ainul, Md. Irfan Hossain, Forhana Rahman Noor, Surojit Kundu, lqbal Ehsan, Eashita Haque, Md. Saddam Hossain, and Mehnaz Manzur. 2020. "COVID-19-related knowledge, attitudes, and practices among adolescent girls in Bangladesh," https://doi.org/10.7910/DVN/UBZXWD, Harvard Dataverse, $\mathrm{V} 1$. 


\section{COVID-19 knowledge of symptoms, transmission, and care seeking}

Overall awareness and knowledge about COVID-19 symptoms and transmission was high and increased over time, but there were specific knowledge gaps such as difficulty breathing as a serious symptom and asymptomatic spread.

\section{Knowledge of symptoms}

- In all three rounds, most girls correctly identified fever, dry cough, sore throat, and runny nose as COVID-19 symptoms.

- Compared to other symptoms, difficulty breathing as a COVID-19 symptom was low, although it increased over time (29\% in Round one and $41 \%$ in the Round three).

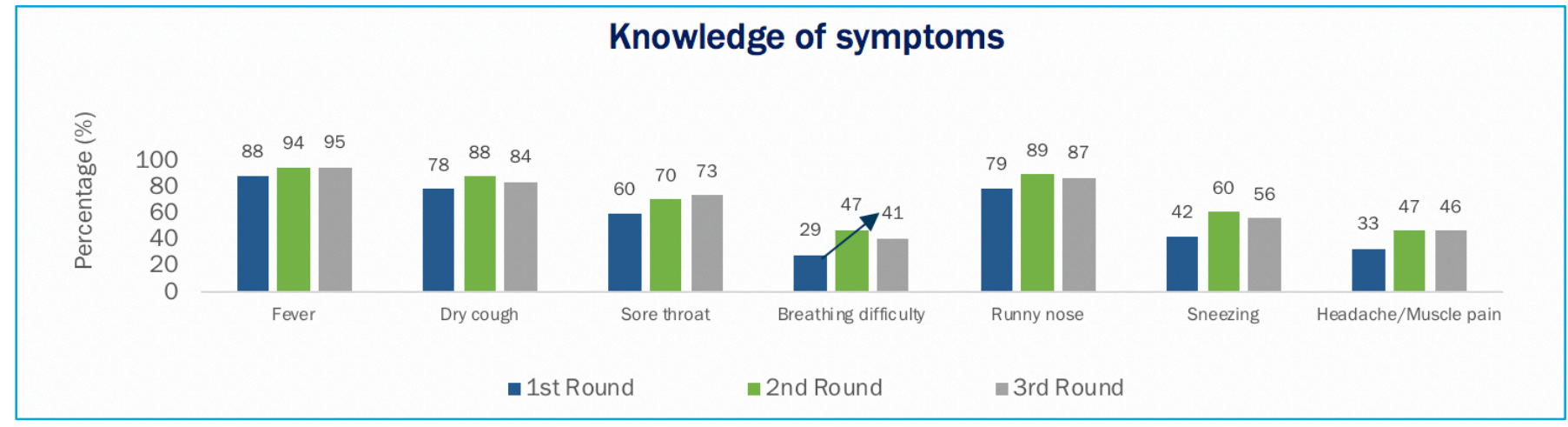

\section{Knowledge of how COVID-19 is spread}

- Direct contact with an infected person is identified as the main route of transmission by the respondents across the three rounds $(67 \%, 83 \%$, and $85 \%)$ followed by cough/sneeze droplets from an infected person ( $57 \%, 73 \%$, and $74 \%)$.

- The knowledge that the virus can be spread by touching contaminated surfaces was high

Knowledge about asymptomatic spread is low $(25 \%)$ and consistent across the three rounds (75\%, 82\%, and $77 \%)$.

- Only 1 in 4 girls across the rounds (21\%, 31\% and 25\%) knew that a person may be COVID-positive and contagious yet asymptomatic.

\section{Knowledge of help-seeking}

- Staying isolated with home-based care (45\%) and calling a government-run helpline (26\%) were the main ways girls sought to get help with COVID-19-related issues in all rounds.

- There is evidence of a shift between Rounds one and three in knowledge of helpseeking options, with more respondents stating a preference for consulting with a local nurse rather than going to the hospital. The response "need to go to hospital/health center" declined (21\% to $8 \%$ to $12 \%$ ), while "consult with neighborhood nurse" increased (28\% to $48 \%$ to $52 \%$ ).

- Perceived stigma associated with coronavirus decreased slightly between Round two (48\%) and Round three (40\%); stigma was not assessed in the first round.

Television and/or

newspaper were reported

as the most trusted

sources of information

(approximately 90\%) in all

three rounds. Exposure to messages about helpseeking received over voice messages and SMS have increased over time $(12 \%$ to $29 \%$ to $21 \%)$.

\section{Prevention practices and social distancing}

Adolescent girls are preventing the spread of coronavirus, but their adherence to social distancing dropped as the countrywide lockdown was lifted.

- Prevention practices-such as using masks, washing hands, and keeping a distance of at least three feet-increased between rounds. (The WHO guidance of three feet is widely accepted in Bangladesh.)

$75 \%$ of adolescent girls used face masks outdoors.

- Social distancing practices such as staying home, stopping interactions with friends, and curtailing social interactions with family and friends decreased or returned to baseline.

- An upward trend in mobility has been found, with average number of days stayed at home decreasing between rounds (from 11 to 5 to 2 days) perhaps because of withdrawal of lockdown. 


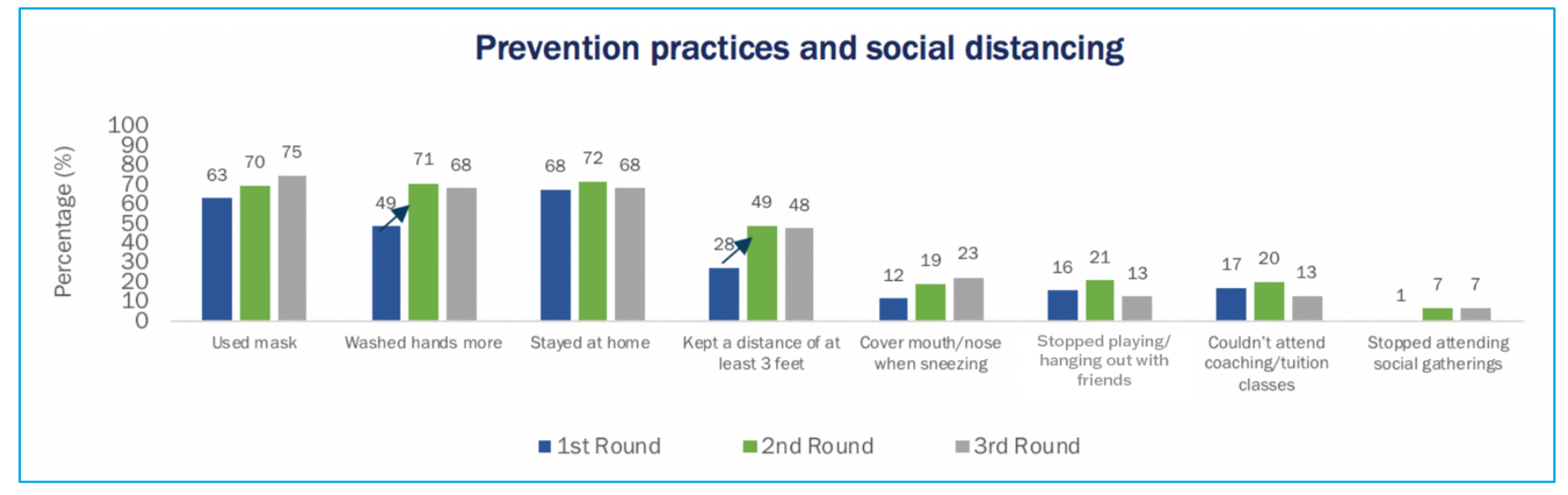

\section{Mental health, violence, time use}

COVID-19 is taking a toll on the mental health of adolescent girls. Social isolation and depressive symptoms increased. In the face of increased economic hardship during COVID-19, adolescent girls, a majority of whom are unmarried and living with their parents, reported experience of violence and unrest.

- By Round three, nearly 8 in 10 adolescent girls reported feeling sometimes or mostly experiencing symptoms of depression-increasing between rounds.

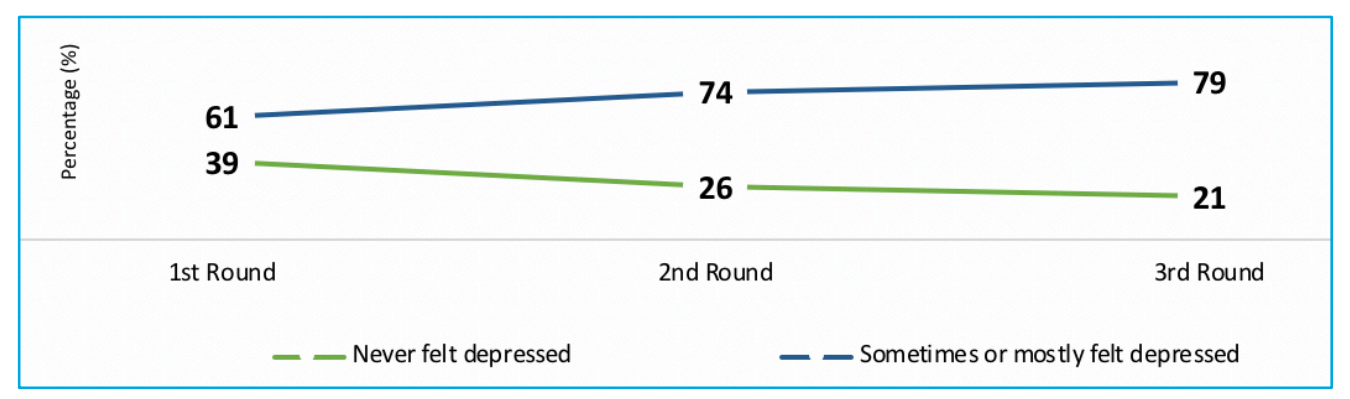

- About 1 in 5 girls reported increased household chores during the pandemic and about 1 in 10 girls reported increased caregiving for a family illness.

- $12 \%$ of adolescent girls reported observing increased violence in their community in the last month-an increase from 3\% reported in Round one.

- Between $1 \%$ to $3 \%$ of girls reported facing some form of violence (rebuke, anger, beating) at home across rounds.

\section{Disruption in education}

Results point to girls' declining engagement in study during school closures.

- Although most girls reported studying independently with help from family members, the percent of girls not studying at all significantly increased from $1 \%$ to $5 \%$ to $10 \%$.

- Classes broadcast by the Ministry of Education over national television are still not widely followed, though attendance has increased to $34 \%$ in Round three compared with earlier rounds ( $21 \%$ to $16 \%$ to $34 \%$ ).

$10 \%$ of adolescent

girls reported the

possibility of not

going back to

school after

reopening.

- $68 \%$ of adolescents are not in favor of automatic grade promotions for the next school year. Among them, $63 \%$ of girls in Round three expressed worry about not being able to cope with the next grade's lessons.

- Girls are spending an average of 2 hours per day studying compared to the 7-8 hours spent in school prior to COVID-19 school closures. 


\section{Child marriage}

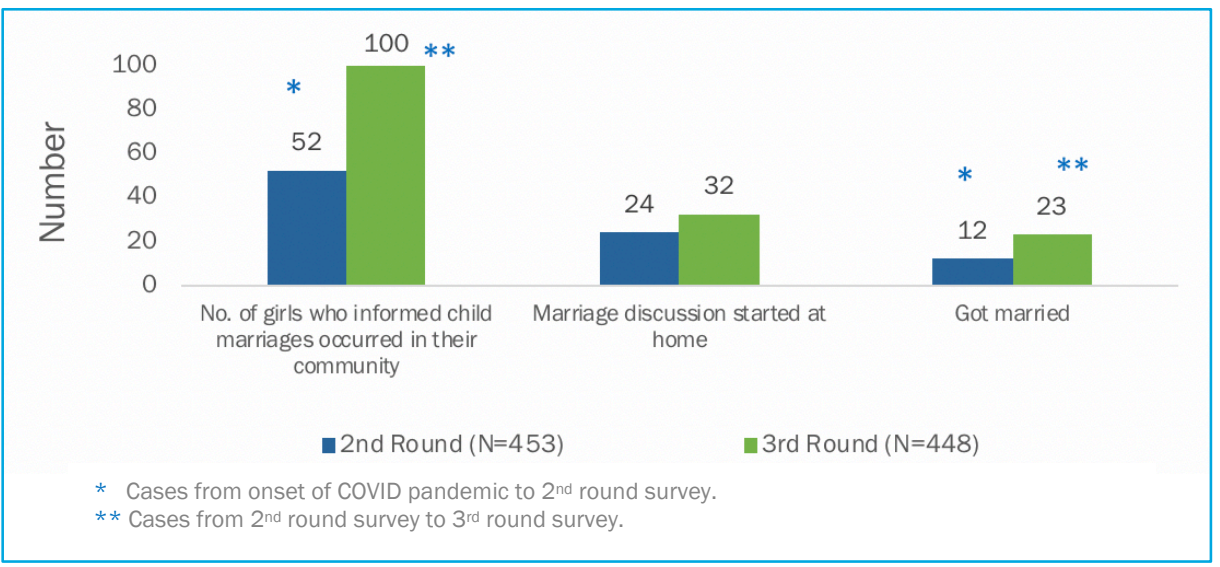

- Girls' reported an increase in their own marriages and marriages of her peers in the community during the pandemic. Out-of-school girls and girls ages 16 and older are at higher risk of child marriage compared to in-school and younger girls.

- Between Rounds two and three, girls also reported hearing their parents talk about their marriage plans.

\section{Economic vulnerability}

Household income has rebounded gradually with the cessation of lockdown, but economic and food security continue to be a major concern.

- In Round three, 44\% reported that their family income has stopped or been reduced severely compared to $69 \%$ in Round 1.

- Households are still cutting back on important needs such as protein in meals, sanitary pads, clothing, and health services.

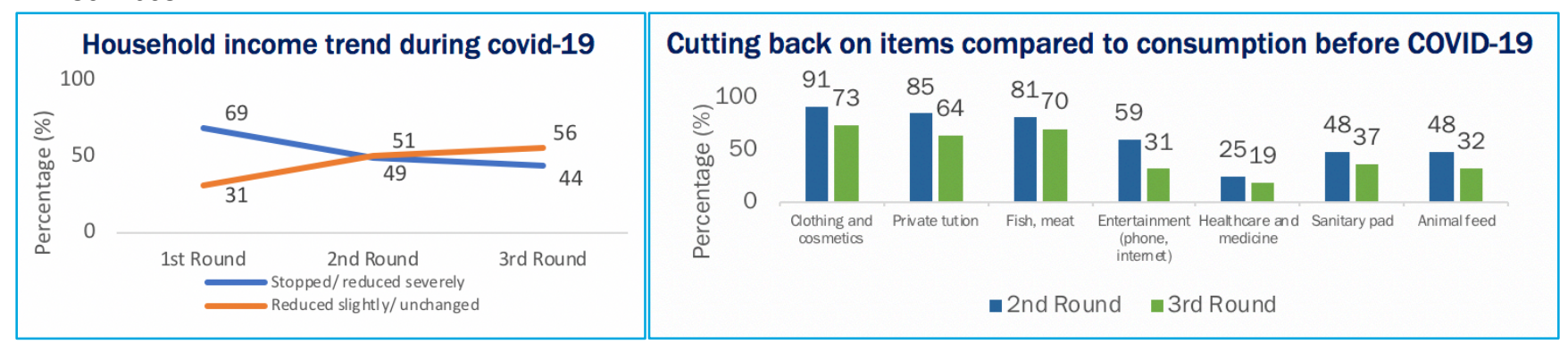

\section{Access to social services/assistance}

- $62 \%$ of adolescent girls were aware of COVID-19 knowledge and awareness campaigns through TV, radio, posters and local community activity, and food or relief programs, which are mainly provided by the government.

- Only $9 \%$ of girls reported receiving aid/services. Of these, $96 \%$ received food and $4 \%$ received government cash transfers.

- There were no reports of girls receiving services related to sexual and reproductive health, mental health, or violence. 


\section{Recommendations}

\section{Focus public education campaigns on information gaps}

Overall, adolescent girls have good knowledge on symptoms and prevention measures, but knowledge could be improved with targeted messaging:

- Develop information campaigns that include messages about asymptomatic spread-to clarify that those not yet showing symptoms are infectious and play a role in the spread of the virus.

- Prepare messages targeted to adolescent girls in order to increase girls' knowledge about the need to maintain a social distance of three feet or more to protect themselves and reduce the risk of COVID transmission.

- Advise adolescents to ensure key prevention practices-wearing suitable masks, maintaining social distance, washing hands regularly, and minimizing exposure-while engaging in social activities as mobility is high across the three districts.

- Use multiple channels to promote public health messages. Consider trust in programming on television and radio and reach for SMS and voice messages.

\section{Support adolescents' education}

- Use mixed models of remote learning and limited in-person engagement for instruction. Distribute materials or worksheets to assist girls who are increasingly feeling detached from their schooling.

- Develop monitoring mechanisms or work assignments that can be submitted to increase the perceived value of continued educational engagement-and to improve attendance and study time.

- Provide guidance to adolescents to address concerns about school expectations and how they will be supported if they are socially promoted in the next academic year. This would alleviate anxiety about grade promotion which may be a factor in decisions to leave school.

\section{Enhance social protections}

- Develop supportive health programming as the health and wellbeing of adolescent girls may worsen as the pandemic continues. Provide mental health services and information that addresses key concerns and other health needs to redress stress and anxiety.

- Ensure food and access to cash transfers for households to address priority needs as households have a direct impact on adolescents. Such programs may also have the added benefit of addressing potential aggression and violence in households.

\footnotetext{
Partnering with national health ministries and other government agencies in sub-Saharan Africa, South Asia, and Latin America, Population Council global and in-country scientists are conducting COVID-19 public health and social science research to produce relevant and timely evidence to support policymakers in controlling the spread of coronavirus, evaluating the effectiveness of prevention and mitigation measures, and assessing longerterm health, social and economic effects of the pandemic.

Suggested citation: Population Council. 2020. "Bangladesh: COVID-19 Knowledge, Attitudes, Practices \& Needs: Responses from three rounds of data collection among adolescent girls in districts with high rates of child marriage."

(C) 2020 The Population Council, Inc.
} 